\title{
A FMEA BASED METHOD FOR ANALYZING AND PRIORITIZING PERFORMANCE RISK AT THE CONCEPTUAL STAGE OF PERFORMANCE PSS DESIGN
}

\author{
Sakwe, John Bake; \\ Pereira Pessoa, Marcus; \\ Hoekstra, Sipke \\ University of Twente
}

\begin{abstract}
With the quest for enhancing competitive position, fulfilling customer and sustainability demands, increasing profitability, asset manufacturing companies are now adapting assets towards product service systems (PSS) offered through performance contracts. Despite several benefits, the shift to performance PSS exposes industrial asset manufacturers' to performance challenges and risks. Currently, PSS designers face a challenge to exhaustively identify potential failures during PSS development. Knowledge of Product failures is critical prior to the engineering of PSS. This paper proposes a failure modes and effects analysis (FMEA) method to support designers' prioritise critical failures in performance PSS development. A case study of an optical sorting machine is used to demonstrate the method's application.
\end{abstract}

Keywords: Product-Service Systems (PSS), Case study, Business models and considerations

\section{Contact:}

Sakwe, John Bake

Fontys

Netherlands, The

j.sakwe@fontys.nl 


\section{INTRODUCTION}

Motivated by fierce competition, manufacturers of high-cost, long-life cycle industrial products in industries such as defence, automobile, aviation, material processing and semiconductors are increasingly expanding or servitising towards product service systems (PSS): product-, use- and performance-oriented business models offered through various contracts (Baines et al., 2007; Datta and Roy, 2010). Literature argues that this expansion is enabled by reusing and adapting previously designed products into PSS to meet market needs (Sundin et al., 2009; Sundin et al., 2005; Lindahl et al., 2009; Copani and Behnam, 2018; Alonso-Rasgado and Thompson, 2006).

Recently, there has been greater interest in performance PSS (Sandborn et al., 2017; Selviaridis and Wynstra, 2015). Performance PSS provides opportunities for manufacturers, such as better control over products through access to data about their conditions, increased profits and improved environmental sustainability (e.g. reusability, increased customer satisfaction) (Tukker, 2004; Rodríguez et al., 2019; Mont, 2002; Baumgartner, 1999; Lindahl et al., 2014).

However, offering performance PSS results in the transfer of failure risks and costs from customer to supplier, which exposes them to potential financial loss if outcome goals are not met (Datta and Roy, 2010; Priya Datta and Roy, 2011; Grubic and Jennions, 2018). Consequently, they face challenges in knowing how to develop the product and providing the required performance e.g. availability levels (Löfstrand et al., 2014). In order to develop and offer PSS successfully, manufacturing firms have to decrease risks (Alonso-Rasgado and Thompson, 2006; Alonso-Rasgado et al., 2004). It is a challenge for designers to exhaustively identify failures at the conceptual stage of PSS development (Kimita et al., 2018).

Despite the state of the arts' contribution to investigating and prioritising failures causes in PSS, Zhang and Chu (2010), Russo et al. (2016), Kurtoglu et al. (2010), Chuang (2007) and Kimita et al. (2018) are some studies that ignore the context of investigation, business model, performance indicators in the contract and performance requirements. They are also unable to link key performance indicators of the contract and the failure cost of critical products or service functions. This limitation could be the reason why it has been difficult to exhaustively investigate failure risks, especially when adapting existing assets into PSS. The research objective for this paper is to support designers in the adaptation of existing assets into PSS through a failure mode and effects analysis (FMEA)-based method for identifying and prioritising failure risks in the conceptual stage of product development. An optical sorting machine is used as a case study to test the proposed method.

The rest of the paper is organised as follows. Section 2 presents performance PSS and a brief literature review. The proposed FMEA-based method for investigating and prioritising failure risks is discussed in Section 3. A case study of an optical sorting machine is introduced in Section 4. Conclusions are drawn and future research direction is presented in Section 5.

\section{PERFORMANCE PSS}

According to Tucker's classification, a performance PSS business model is one in which the service provider sells equipment performance, function or results to a customer instead of products; however, the provider retains product ownership (Tukker, 2004). Various types of performance PSS are presented by Tukker (2004): activity management or outsourcing, pay-per-service unit and functional results. Product/service functionality and results are extremely important in performance PSS provision (Lindström, 2016; Reim et al., 2015; Aurich et al., 2006b; Aurich et al., 2006a; Van Ostaeyen, 2014b). According to Van Ostaeyen et al. (2016), the functional performance of a system describes how well its functions or intended purposes are performed. Meanwhile, performance results are a standardised unit of functional delivery, e.g. availability of the functions (Van Ostaeyen et al., 2013). Various performance measures are discussed in performance PSS, including availability, productivity, quality and efficiency, flexibility, technical specifications and safety (Sandborn et al., 2017; Lindström, 2016; Richter et al., 2010; Maussang et al., 2009; Van Ostaeyen, 2014a; Hensher and Stanley, 2003). The performance agreement of the product service system is specified in the contract. The performance indicators in performance PSS business models are important when providing performance PSS and these indicators are also specified in the contract (Van Ostaeyen, 2014a). 


\subsection{Research Background}

Even though there are tools and methodologies supporting manufacturing industries in their quest to make the transition from stand-alone products and services to industrial product services systems, Trevisan et al. (2016) argue that one of the most significant gaps in PSS is the lack of methodologies in the early design stages of product and service development. This issue is exacerbated in performance PSS, where manufacturers are compelled to profitably meet the performance agreements written in the contract. Manufacturers are exposed to performance and business risks, coupled with the cost for delivering the solution (Datta and Roy, 2010; Hou and Neely, 2018). Thus, knowing the inherent product failures and costs is highly important for performance PSS development. This knowledge can support manufacturing companies to improve the asset in line with the requirements of the contract, thus offering performance PSS successfully.

Some studies have applied FMEA in product and service design to analyse and increase the reliability of PSS. In their study, Kimita et al. (2018) proposed an FMEA framework that enabled designers to conduct the integrated analysis of product and service failures for PSS based on object-oriented models during the conceptual design stage of cleaning machines. This could be achieved by utilising the view model and extended service blue printing. Zhang and Chu (2010) applied an FMEA tool to identify and analyse failure modes and their effects on product concepts for drilling machines (Zhang and Chu, 2010). Kurtoglu et al. (2010) propose a functional FMEA to aerospace electrical power systems to support designers in exploring risks and flaws during the early functional design stage. To design a hypermarket service system, (Chuang, 2007) proposed an FMEA and service blueprinting to prioritise critical failure modes of the service, and then proposed actions to ensure the adequate performance of service design. In their paper (Russo et al., 2016) combined FMEA and the theory of inventive problem solving (TRIZ) to determine the root causes of failures in a crane. The work of Erkoyuncu et al. (2009) proposed a cost estimation approach, considering mean time to repair (MTTR) and mean time between failures (MTBF). To decrease the risks of changing customer requirements in PSS contracts, Richter et al. (2010) applied a modular design and then quantified manufacturer's benefits. In their work, Legnani et al. (2010) proposed a preventive maintenance strategy to improve service performance. It can be concluded from these studies that FMEA, alongside functional analysis, is a useful tool to investigate failure risks in product service development.

Furthermore, when applying FMEA, it is important to, 1) identify failures based on product, service or product and service system, 2) identify the failure causes, 3) determine failure effect and, 4) determine risks level. The risk level then becomes the basis for design improvement. However, the reviewed literature ignores the business model, the performance indicators in the contract, the context of the investigation and performance requirements. They also did not identify the link between key performance indicators of the contract and the failure costs of the critical product/service. This limitation could be the reason why it is difficult to exhaustively investigate risks during product service development, and could be the reason why some manufacturers find it difficult to achieve the expected profit (Neely, 2008). To deliver reliable products and services while minimising efforts and costs, we propose a procedure for analysing and prioritising performance risks during the conceptual stage of performance PSS development.

\section{THE PROPOSED METHOD}

Based on the requirements identified in the previous section and considering the gaps identified, we propose an FMEA-based approach for identifying performance risks in performance PSS development. To create the proposed method, the key requirement identified in the literature review was used as a basis for the proposed steps in the method. Figure 1 is the proposed FMEA-based method for analysing and prioritising failures in performance PSS development. 


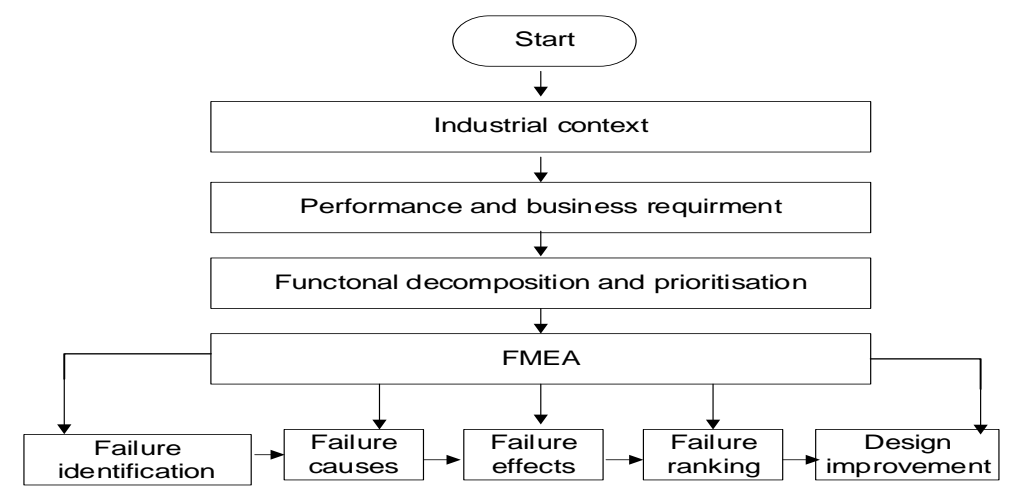

Figure 1. FMEA-based method for analysing failures in performance PSS development.

Step 1. Context Definition

Since offering PSS is very context dependent (e.g. depends on industrial product service systems and PSS), it is important to clarify the aspects and services that make up the business model (e.g. outsourcing, pay-per-service unit and functional results). Next, product-based services need to be specified. Examples of services are corrective maintenance, preventive maintenance, training and installation. This phase can be executed via interviews or focus group discussions with stakeholders.

Step 2. Performance and Business Requirement

Furthermore, knowledge from PSS engineering clearly stresses the relevance of making sure requirements are completely met. Thus, stakeholders' requirements and performance indicators should be adequately defined. Here, interviews can be used to investigate customers' product service functional requirements and service level agreements in the contract, e.g. downtime, availability/uptime and mean time to meet service request. In addition, business needs are also important to investigate. Business needs include profit, cost reduction, service efficiency and sustainability.

Step 3. Functional Decomposition and Prioritisation

As it is challenging to exhaustively investigate all failure modes of multifunctional products, the key functions of the product are then decomposed and selected based on risks for the manufacturer and industrial customers. This decomposition process, as depicted in Figure 2, can be performed on different levels of abstraction depending on the complexity of the asset: assembly, sub-assembly and component. The functions are prioritised based on their failures, downtime cost and amount of downtime.

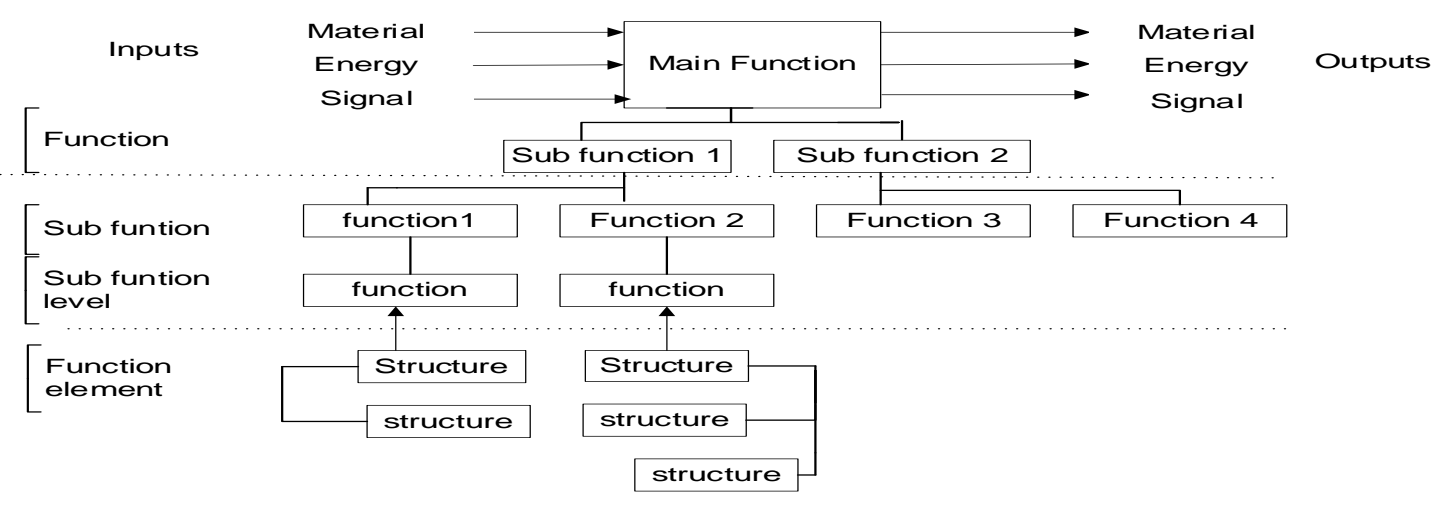

Figure 2. Functional decomposition modelling 


\section{Step 4. FMEA}

Based on the information above, the designer analyses what components may fail to deliver the desired functional performance. The input for this stage is information from maintenance engineers or service engineers of the company. Furthermore, failure information can be accessed via the internal maintenance records of the asset. Here, failure is described as a loss of system critical function. The outputs for this sub-step are the critical failures. Through analysing the system's failures, the most essential sub-systems and the system's failures are presented. A failure is when a component fails to function correctly, which can be noticed through some kind of abnormal behaviour (e.g. vibration, product defects). FMEA is suitable to perform this analysis, as it prioritises vital failures. In other words, the designer is aware of components that could fail to meet the performance agreements. To prioritise these failures and failure modes, FMEA is used as shown in Table 1. S, P and D refer to severity, probability and detectability, respectively. RPN is a product of S, P and D. The outcome of this phase provides a basis for system improvement.

\section{CASE STUDY}

Due to confidentiality reasons, the case company decided to remain anonymous. Thus, the company will be referred to as Sorting Machines Manufacturer (SMM). The company is considering expanding to performance PSS. The most promising expansion strategy is selling products' actual performances (e.g. total sorting volume, availability). Proprietary rights are retained by the manufacturer. Benefits for customers include low-cost, high-quality products and high rates of customer satisfaction. For the manufacturer, the decision to expand is motivated by profit margins, sustainability and customer demands. Due to regulations, product inspection requires an automated inspection process instead of manual operations. Figure 3 is an example of an optical sorting machine.

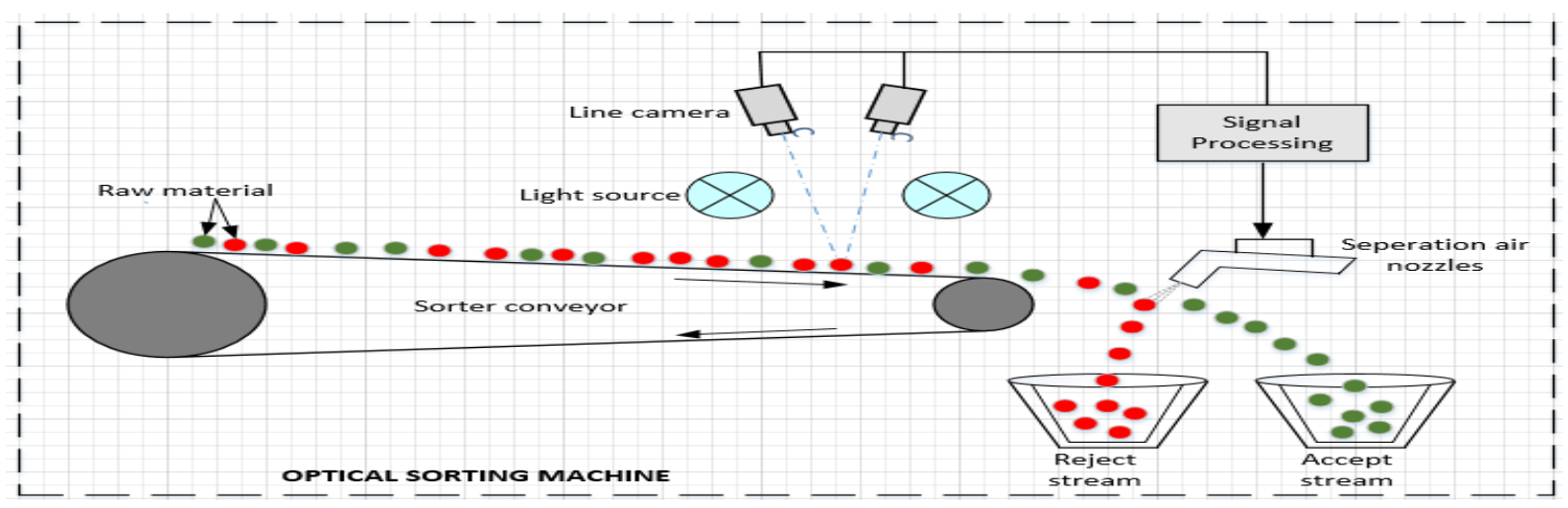

Figure 3. Overview of an optical sorting machine adapted from (EagleVision, 2020)

Phase 1. Context Description

Optical sorting machines are machines equipped with conveyor belts running at high speeds. They are used to inspect products in the food and material handling industry (e.g. potatoes, carrots and green beans). Customers of these machines demand high-quality products; however, the demand for food is also high. To accommodate these demands, an automated system such as the optical sorting device is critical. The optical device is composed of hardware including cameras, lasers, x-rays and some mechanical components controlled through a customised PC-based software. Currently, the product is sold on a transaction basis via a B2B relationship, and add-on services such as corrective maintenance/repair are offered as part of an ongoing warranty contract.

Phase 2. Performance and Business Requirements

The goal of this phase was to obtain information of performance and business requirements; this phase was completed through interviews. Interviews with customers reveal that customer performance demands are reduction in downtimes. Currently, the contracted level of downtime is a maximum of 24 hours from the moment a problem is reported by a customer. This includes on weekends. For 
customers, downtime should be decreased even further. Downtime for the customer is very costly because of the high-volume production systems. Furthermore, the contract states some specifications regarding product quality; customers expect precision in the sorting of the products and a reduction in the amount of false rejections and defects in a sample badge.

\section{Step 3. Functional Decomposition and Prioritisation}

The key functions of the optical sorting machine are then decomposed using functional analysis. The exercise was completed by the service engineer assigned for this project and the researcher. Figure 3 is an overview of this decomposition process, which includes processing, material handling, detection and separation. The functions are first prioritised based on cost, as shown in Figure 4. Material handling is done to ensure that the product is effectively presented for optical inspection. The detection function helps to take live images of the materials. The processing function processes these images and makes a decision based on the quality specification input from the operator.

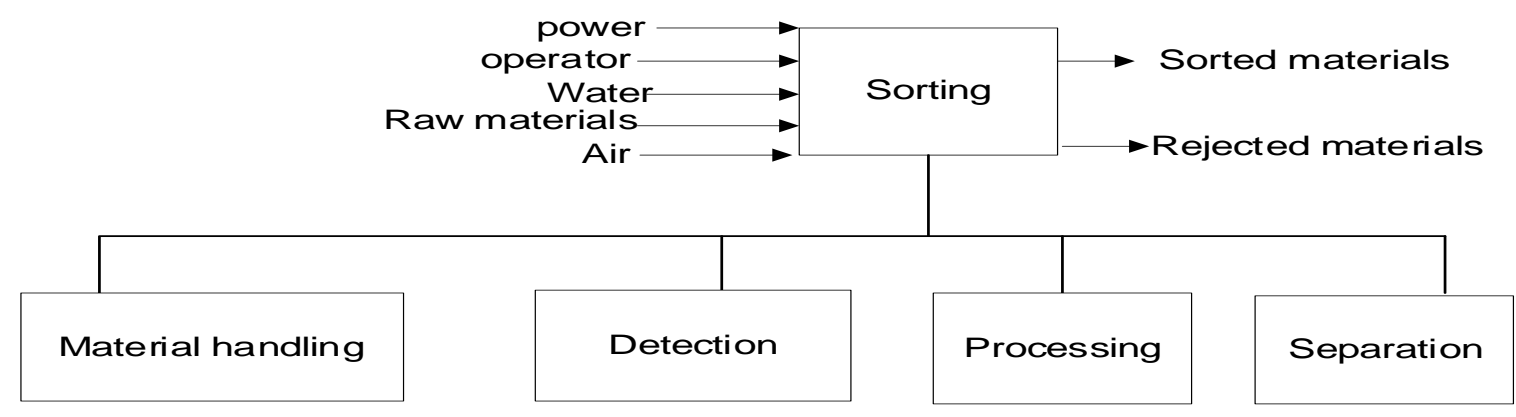

Figure 4. Assembly level decomposition of systems functions.

Based on the information above, the designer analyses what functions present the biggest risks for the manufacturer. The cost structure of each assembly provides input for prioritising the critical functions. The input of this stage comes from the maintenance engineers or service engineers of the company. Furthermore, failure information was also accessible via internal maintenance records of the asset. Here, failure is defined as a loss of system critical function. The outputs are the critical failures and failure modes. The analysis, as shown in Figure 5, shows that three key functional assemblies (the cleaning system, lighting system and conveyor system) were responsible for most of the failures and costs.

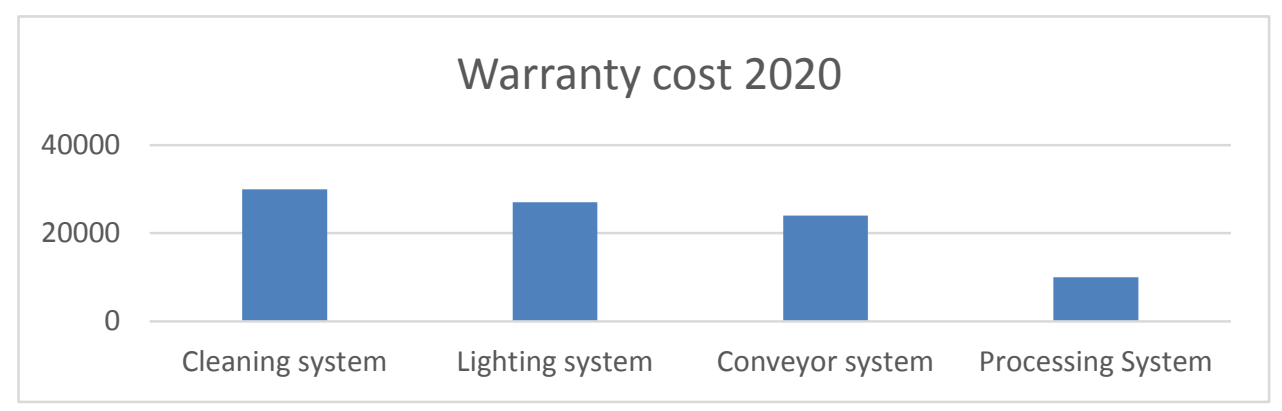

Figure 5. Cost overview of the machines' assemblies.

Step 4: Failure Modes Analysis

The inputs of this stage are the failures observed in the historic data of the manufacturer involved in servicing, the current equipment and knowledge from the field service manager of the company. Having analysed the system's failure data, the most essential sub-systems and the failures are presented and ranked in terms of probability of failure, frequency, detectability and calculation of RPN for the components of the assemblies. The service engineers were asked questions such as, 'what are the critical failures impacting system downtime?', 'what is the cost of these failures?' and 'how much time is spent to ensure that the system is restored to its working state?' Information was then pulled from reliability systems, enterprise resource planning and the maintenance data base. In the presented illustration, the critical functional failures that the company is concerned about are the lighting system, 
conveyor system and cleaning system. Table 1 is an overview of the FMEA for the various systems of the optical sorting machine.

Table 1. Failure modes and effects analysis

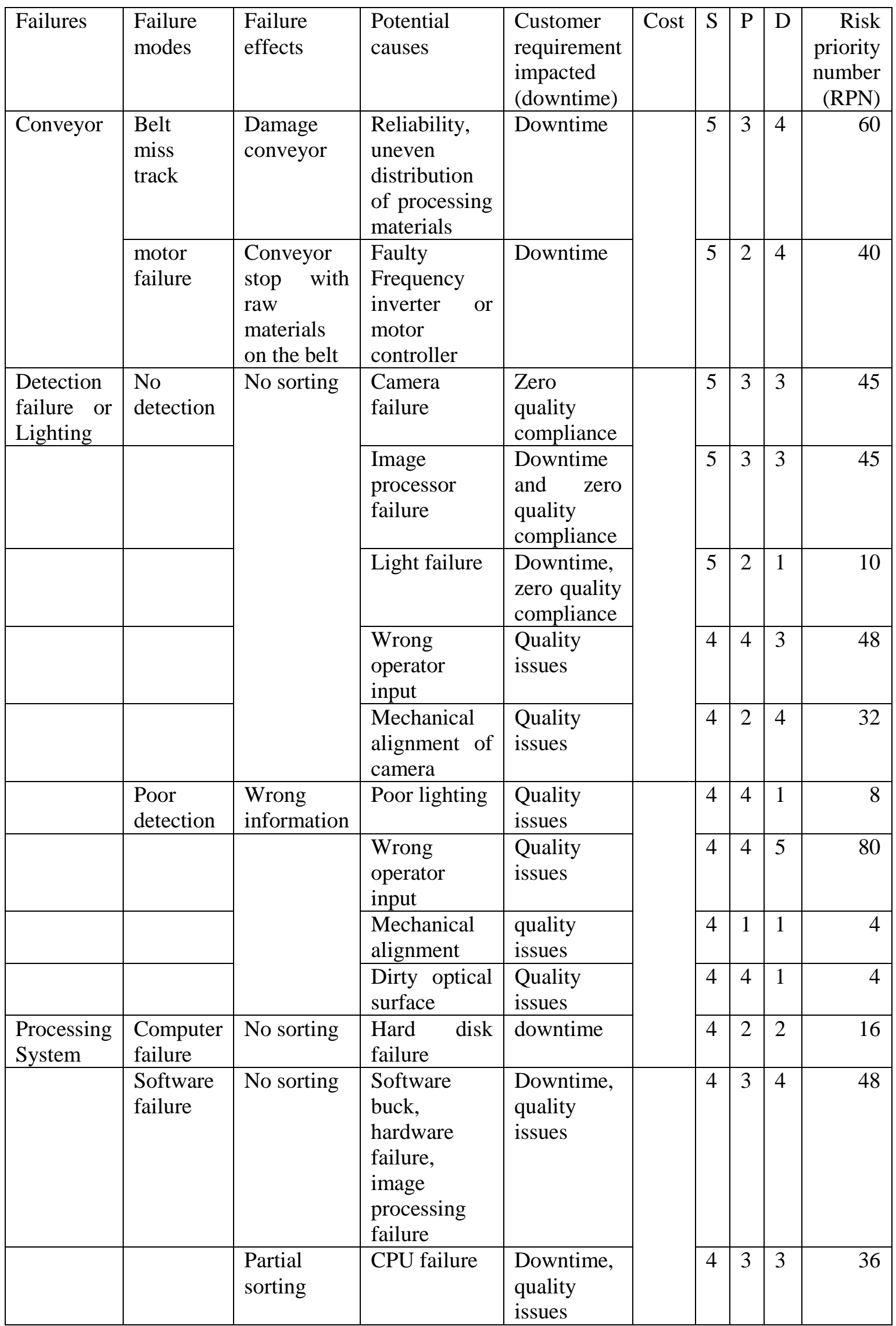




\begin{tabular}{|c|c|c|c|c|c|c|c|}
\hline & & $\begin{array}{l}\text { Software } \\
\text { buck, } \\
\text { hardware } \\
\text { failure }\end{array}$ & $\begin{array}{l}\text { Downtime, } \\
\text { quality } \\
\text { issues }\end{array}$ & 4 & 3 & 3 & 36 \\
\hline \multirow[t]{4}{*}{$\begin{array}{l}\text { Cleaning } \\
\text { System }\end{array}$} & Sprayer & $\begin{array}{l}\text { Sprayer } \\
\text { malfunction }\end{array}$ & downtime & 4 & 4 & 5 & 80 \\
\hline & Shuttle & $\begin{array}{l}\text { Defective } \\
\text { shuttle }\end{array}$ & $\begin{array}{l}\text { Poor } \\
\text { product } \\
\text { quality }\end{array}$ & 4 & 3 & 4 & 48 \\
\hline & Wiper & $\begin{array}{l}\text { Defective } \\
\text { wiper }\end{array}$ & $\begin{array}{l}\text { Poor } \\
\text { quality }\end{array}$ & 3 & 4 & 3 & 36 \\
\hline & Brackets & $\begin{array}{l}\text { Defective } \\
\text { brackets }\end{array}$ & downtime & 5 & 3 & 5 & 75 \\
\hline
\end{tabular}

The riskiest sub systems and components arising from this investigation will provide input for decreasing downtime through improvements in the product. The conveyor, lighting and cleaning systems are the major subsystems and functions that are critical in terms of downtime and cost for the provider, key areas for mitigating risks include, sprayer, belt, motto, operator, brackets camera.

\section{CONCLUDING REMARKS AND FUTURE RESEARCH DIRECTION}

The paper presents an objective study of an FMEA method for investigating failure risks in performance PSS. This method can provide knowledge of critical failures in line with the agreements written in the contract and provides a basis for making design improvements to fulfil stakeholder requirements. The results of this case study are promising. However, the study suffers from using only one case study. This is mainly due to the fact that the research is an ongoing research. Furthermore, the aspect of the business model was not deeply investigated. Future research could investigate how the inputs of such an investigation could actually help to reduce the failure risks e.g. through the integration of digital technologies at the development stage of the product service. The proposed method could also be implemented in other business contexts, e.g. for different products services and industries.

\section{REFERENCES}

Alonso-Rasgado, T. \& Thompson, G. (2006) 'A rapid design process for total care product creation', Journal of Engineering Design, vol. 17, 509-531. https://doi.org/10.1080/09544820600750579.

Alonso-Rasgado, T., Thompson, G. \& Elfström, B. O. E. (2004) 'The design of functional (total care) products', Journal of Engineering Design, vol. 15, 515-540. https://doi.org/10.1080/09544820412331271176.

Aurich, J. C., Fuchs, C. \& Wagenknecht, C. (2006a) 'Life cycle oriented design of technical Product-Service Systems', Journal of Cleaner Production, vol. 14, 1480-1494. https://doi.org/10.1016/j.jclepro.2006.01.019.

Aurich, J. C., Fuchs, C. \& Wagenknecht, C. (2006b) Modular design of technical product-service systems, Dordrecht, Springer Netherlands. https://doi.org/10.1007/1-4020-4617-0_21.

Baines, T. S., Lightfoot, H. W., Evans, S., Neely, A., Greenough, R., Peppard, J., Roy, R., Shehab, E., Braganza, A. \& Tiwari, A. (2007) 'State-of-the-art in product-service systems', Journal of Engineering Manufacture, vol. 221, 1543-1552. https://doi.org/10.1243/09544054JEM858.

Baumgartner, P. (1999) 'Go downstream. The new profit imperative in manufacturing', Harvard Business Review, vol. 77.

Chuang, P. T. (2007) 'Combining service blueprint and FMEA for service design', The Service Industries Journal, vol. 27, 91-104. https://doi.org/10.1080/02642060601122587.

Copani, G. \& Behnam, S. (2018) 'Remanufacturing with upgrade PSS for new sustainable business models', CIRP Journal of Manufacturing Science Technology, vol. 29, pp. 245-256. https://doi.org/10.1016/j.procir. 2016.03.055.

Datta, P. P. \& Roy, R. (2010) 'Cost modelling techniques for availability type service support contracts: A literature review and empirical study', CIRP Journal of Manufacturing Science and Technology, vol. 3, 142-157. https://doi.org/10.1016/j.cirpj.2010.07.003.

EagleVision. (2020). Optical sorting - how it works. Available Online at: http://www.eaglevizion.com/ optical_sorting, access on 17/062020. 
Erkoyunca, J. A., Roy, R., Shehab, E. \& Wardle, P. (2009) Uncertainty challenges in service cost estimation for product-service systems in the aerospace and defence industries. Proceedings of the 19th CIRP Design Conference-Competitive Design. Cranfield University Press.

Grubic, T. \& Jennions, I. (2018) 'Do outcome-based contracts exist? The investigation of power-by-the-hour and similar result-oriented cases', International Journal of Production Economics, vol. 206, 209-219. https://doi.org/10.1016/j.ijpe.2018.10.004.

Hensher, D. A. \& Stanley, J. (2003) 'Performance-based quality contracts in bus service provision', Transportation Research Part A: Policy Practice, vol. 37, 519-538.

Kimita, K., Sakao, T. \& Shimomura, Y. (2018) 'A failure analysis method for designing highly reliable productservice systems', Research in Engineering Design, vol. 29, 143-160. https://doi.org/10.1007/s00163-0170261-8.

Kurtoglu, T., Tumer, I. Y. \& Jensen, D. C. (2010) 'A functional failure reasoning methodology for evaluation of conceptual system architectures, Research in Engineering Design, vol. 21, no. 4, pp. 209-234. https://doi.org/10.1115/1.2885181.

Legnani, E., Cavalieri, S., Marquez, A. C. \& DÍAZ, V. G. System Dynamics modeling for Product-Service Systems: A case study in the agri-machine industry. Proc. of APMS, 2010.

Lindahl, M., Sakao, T., Sundin, E. \& Shimomura, Y. (2009) Product/service systems experiences: an international survey of Swedish, Japanese, Italian and German manufacturing companies. 1st CIRP Industrial Product-Service Systems (IPS2) Conference, Cranfield University UK, 1-2 April 2009, 2009. Cranfield University Press, 74-81.

Lindahl, M., Sundin, E. \& Sakao, T. (2014) 'Environmental and economic benefits of Integrated Product Service Offerings quantified with real business cases', Journal of Cleaner Production, vol. 64, 288-296. https://doi.org/10.1016/j.jclepro.2013.07.047.

Lindström, J. (2016) 'When Moving from Products and Services towards Functional Products: Which Sustainability-oriented Customer Values are of Interest?', Procedia CIRP, vol. 48, 16-21. https://doi.org/10.1016/j.procir.2016.03.027.

Löfstrand, M., Kyösti, P., Reed, S. \& Backe, B. (2014) 'Evaluating availability of functional products through simulation', Simulation Modelling Practice Theory, vol. 47, 196-209. https://doi.org/10.1016/j.simpat. 2014.05.011.

Maussang, N., Zwolinski, P. \& Brissaud, D. (2009) 'Product-service system design methodology: from the PSS architecture design to the products specifications', Journal of Engineering Design, vol. 20, 349-366. https://doi.org/10.1080/09544820903149313.

Mont, O. K. (2002) 'Clarifying the concept of product-service system', Journal of Cleaner Production, vol. 10, 237. https://doi.org/10.1016/S0959-6526(01)00039-7.

Neely, A. (2008) 'Exploring the financial consequences of the servitization of manufacturing', Operations Management Research, vol. 1, 103-118. https://doi.org/10.1007/s12063-009-0015-5.

Priya Datta, P. \& Roy, R. (2011) 'Operations strategy for the effective delivery of integrated industrial productservice offerings: two exploratory defence industry case studies’, International Journal of Operations \& Production Management, vol. 31, 579-603. https://doi.org/10.1108/01443571111126337.

Reim, W., Parida, V. \& Örtqvist, D. (2015) 'Product-Service Systems (PSS) business models and tactics - a systematic literature review', Journal of Cleaner Production, vol. 97, 61-75. https://doi.org/10.1016/ j.jclepro.2014.07.003.

Richter, A., Sadek, T. \& Steven, M. (2010) 'Flexibility in industrial product-service systems and use-oriented business models', CIRP Journal of Manufacturing Science and Technology, vol. 3, 128-134. https://doi.org/10.1016/j.cirpj.2010.06.003.

Rodríguez, A. E., Pezzotta, G., Pinto, R. \& Romero, D. (2019) 'A Comprehensive Description of the ProductService Systems' Cost Estimation Process: An Integrative Review', International Journal of Production Economics, vol. 221.https://doi.org/10.1016/j.ijpe.2019.09.002.

Russo, D., Birolini, V. \& Cerelosi, R. (2016) 'FIT: A TRIZ Based Failure Identification Tool for ProductService Systems’. Procedia CIRP, vol. 47, 210-215. https://doi.org/10.1016/j.procir.2016.03.087

Sandborn, P., Kashani-Pour, A., Goudarzi, N. \& Lei, X. (2017) 'Outcome-based contracts-towards concurrently designing products and contracts’. Procedia CIRP, vol. 59, 8-13. https://doi.org/10.1016/j.procir.2016. 09.017.

Selviaridis, K. \& Wynstra, F. (2015) 'Performance-based contracting: a literature review and future research directions', International Journal of Production Research. vol. 53, 3505-3540, https://doi.org/10.1080/ 00207543.2014.978031.

Sundin, E., Larsson, M. \& Nielson, A. (2005) 'Design for functional sales-a case study of forklift trucks at BT industries’, 2005 4th International Symposium on Environmentally Conscious Design and Inverse Manufacturing, 378-385. https://doi.org/10.1109/ECODIM.2005.1619250.

Sundin, E., Lindahl, M. \& Ijomah, W. (2009) 'Product design for product/service systems: Design experiences from Swedish industry’, Journal of Manufacturing Technology Management, vol. 20, 723-753. 
Tukker, A. (2004) 'Eight types of product-service system: eight ways to sustainability? Experiences from SusProNet', Business strategy and the environment, vol. 13, 246-260. https://doi.org/10.1002/bse.414

Van Ostaeyen, J. (2014a) 'Analysis of the business potential of product-service systems for investment goods. Faculty of Engineering Science, KU Leuven.

Van Ostaeyen, J. (2014b) Analysis of the Business Potential of Product-Service Systems for Investment Goods (Analyse van het zakelijk potentieel van product-dienstsystemen voor investeringsgoederen).

Van Ostaeyen, J., Van Horenbeek, A., Pintelon, L. \& Duflou, J. R. (2013) 'A refined typology of productservice systems based on functional hierarchy modeling', Journal of Cleaner Production, 51, 261-276. https://doi.org/10.1016/j.jclepro.2013.01.036.

Zhang, Z. \& Chu, X. (2010) 'A new approach for conceptual design of product and maintenance', International Journal of Computer Integrated Manufacturing, vol. 23, 603-618. https://doi.org/10.1080/09511921003 736766. 